\title{
Application Analysis on Traditional Hangings Decorative Art in Modern Interior Design
}

\author{
Zhou Xiao \\ Architecture and Urban Planning College, Southwest University for Nationalities, Chengdu Sichuan, \\ 610041, China
}

Key Words: Modern interior design, Traditional hangings, Decorative art

\begin{abstract}
Traditional hangings are simple, unsophisticated, elegant and exquisite enough to show the unique national aesthetic taste and artistic vitality of our country. It has become one of the important components of traditional art in China, offering vital reference value for modern engraving, handicraft, plane design, interior design, etc. Due to the development of globalization and the rise of restorative trend, the valuable elements in Chinese traditional culture are more and more widely applied in modern design. Traditional hangings are widely applied in modern interior design, generating brand new Chinese style hanging decorative art. This paper on basis of overview of traditional hangings elaborates main materials of traditional hanging decorative art, and discusses the methods of applying traditional hanging decorative art in modern interior design and modern public space design.
\end{abstract}

\section{Introduction}

Traditional hanging, as one of the components under girders and at both sides of columns in Chinese traditional architecture, is generally made of hollow wood grids or carving board and even connected by small battens. It is used for decoration or interior room division. Hanging in Chinese traditional architecture generally decorates the key parts with openwork carving or colored drawing. Nowadays, more and more interior designers attempt to apply some elements of Chinese traditional culture into their designs, or show simple Chinese style decorative style as a whole, or present Chinese traditional culture symbols with modern expression techniques and materials. Chinese traditional culture is rich. Plenty of classical garden design, palace design, and residential house design provide sufficient exhibition of traditional culture elements. Therefore, Chinese traditional hanging decorative art should be applied to actual design in current modern interior design process. Only in this way can the interior room decoration of modern people show full-bodied Chinese style.

\section{Overview of traditional hanging}

Traditional hanging, as one of the decorative components under girders and at both sides of columns in architecture, is generally made of successional wood carving or jointly constructed by wood latticework and carving like interior flower shade. For example, such kind of hanging can usually be seen in residence of Huizhou, Anhui Province, which is generally composed of plant, flower and bird, dragon and phoenix, etc. It is decorated densely under girders or between columns, adopting the technique of combination of deep carving and openwork carving with trespe, floral leaf, or bats pattern as embellishment. Lattices hanging under girders or between columns in form of wood can be taken apart at any time. Kwai-type Wanchuan hanging is the most common one. Traditional hanging art is a kind of decorative art with a long history and wide application. It is able to separate the room, making the originally monotonous space with even more vertical feeling and layering so that 
residents can realize the respective effects of different spaces. Traditional hanging is mainly used in interior design whose size is not too big. In this way, the layout will be more reasonable and more suitable for the simple space concept advocated by modern design.

\section{Main materials of traditional hanging decorative art}

Chinese traditional hanging has rich materials which can be concluded into two categories namelyఔ pattern and twine pattern. “艺” originates from a kind of talisman in remote antiquity of China, which is generally considered as the symbol of sun or fire. The original meaning of “‡”” in Sanskrit is "concentrated reflection of luckiness" and is then extended to the meaning of being eternal, counteracting evil force and reaching good fortune. It can be seen from current archaeological discoveries that " $Z$ " has become the symbol of all kinds of auspicious words which begin with a Chinese character as "Wan". It is the most prominent representation of Chinese traditional folk art products. “¿” applied in traditional hangings mainly starts from simpleness to complexity and from single to double. Four ends extend and connect with each other, forming the pattern called Swastika brocade or Swastika with long feet. “艺” is usually carved on the girder of some traditional architecture, meaning "no decollation of riches and honour” believed by the ancient people. “艺” is also connected with Chinese nation's traditional culture psychology of loving luckiness and hoping for racial continuation, forming auspicious meanings of looking forward to new life reproduction and getting rid of disaster. It is exactly due to Chinese people's pursuit of beautiful life and implied meaning of going after various kinds of beauty that makes these images handed down from age to age and makes these images richer and richer. Twine pattern, called "Twine Flower" or "Wanshou Cirrus", is a very important type of Chinese traditional decorative patterns. It is generally considered that twine pattern originates from the Han Dynasty and becomes prevalent in the Northern and Southern Dynasties as well as the following dynasties. In Ming Dynasty, it was also called "Twisty Branch" which usually took plant branch or cirrus as main framework and then extended towards all directions, forming curve continuation and generating endless changes through circulation. The traditional auspicious patterns are created with cirrus or trespe. "Twine" in twine patterns always takes climbing plants like ivy, honeysuckle and Boston ivy as its prototype, showing swaying and vivid images. It implies the happiness that can last a long period of time and has become Chinese traditional classic auspicious pattern.

\section{Methods of applying traditional hanging decorative art in modern interior space design}

How to accomplish the enclosure of architecture is a kind of important art, so the feelings of living in big houses and small houses are quite different from each other. Palace such as the Palace Museum in Beijing must be the most typical one in Chinese traditional types of architectural space. Hangings have achieved large-scale application in royal palace. Furthermore, Qiao's Grand Courtyard, where the representative personage of Qiao and the famous businessman in Qing Dynasty named Qiao Zhiying lived, must be the most representative one of Shanxi merchants' courtyards. Wood carvings in this courtyard have exquisite modeling, great originality, and wonderful article excelling nature, especially the striking wood carving hangings on front arch. There are in total 14 wood carving hangings in Qiao's Grand Courtyard and 3 of them are kept in Zhongxiandi with very graceful modeling, exquisite carving means, and extremely rich implied meaning. All these are of top grade of wood carving hangings on front arch of Qiao's Grand Courtyard. They are also a representative of hanging art in royal palace and residence. Hanging style is also widely applied in the interior space design of well-known private garden in Yangzhou Jiangsu. It aims to separate and transfer relevant space. Of course, creation of new space, especially space with new property, is also the purpose of hanging decorative art application. New property means more than the sum of two parts, which refers to the construction from partial to integral. Interior space design is usually confronted with situations 
that the separation must be realized in limited space. If hangings can be used for separation, new space can be formed without changing the current situations.

Designing the separation and connection of current interior space is $\mathrm{n}$ longer merely technical matter but an artistic matter. Except for taking space separation and connection of functional operating requirements into consideration, its form, organization, orientation, line, constitution and entire distribution management all have very significant reference value for space design. They are able to reflect the characteristics and style of interior design as well as the understanding and thought of interior designers. The usage of hanging decoration in interior space generally lies in how to deal with the relationship between closed space and open space, space transition and space continuation, open space and secret space. As a result, hanging decoration elements should be applied to the process of current living space design and many Chinese style decoration and design processes. Afterwards, the space should be separated and beautified. Such kind of design is suitable for those older people and those who love Chinese traditional culture.

\section{Methods of applying traditional hanging decorative art in modern public space design}

In process of modern public space decoration design, there are also many spaces that need separation and transition. For example, in the office space of modern office buildings, the majority of offices will set moving space for purpose of receiving a visitor, make arrangements, and realizing reception. In addition, there are also relatively "quiet" spaces for purpose of independent official business. When the moving and quiet spaces need to be separated, the space area is usually limited. Under such kind of situation, hangings can be used for simple separation so that the actual effects of beautifying the spaces can be realized. For example, the workplace design of a famous enterprise Yangzhou Lacquerware Co. Ltd adopts the style of close combination of nature and tradition, while the wide application of traditional hangings has already become the mainstream of space design in office buildings. It realizes in-depth combination of lacquerware craft and traditional hangings as well as the in-depth combination of lacquerware hangings and modern interior design style, emphasizing the distinct characteristics of Chinese traditional artware manufacturers. Furthermore, some dining rooms or banquet halls with Chinese decoration style will also use traditional hangings for separation. Yangzhou State Guesthouse in Jiangsu adopts the form of hangings in its Chinese style dining rooms to separate the rest space and dining space for guests. It is the same with many ancient towns and restaurants and tea house in old streets. Their waiting rooms are all decorated with traditional hanging elements. Therefore, taking traditional hanging decorative art as artistic means and applying it in space design can realize favorable leading and separating effects, and also reflect practical value, sense of privacy, safety performance, etc. In this way, the general standard and level of the spaces can be improved. Taking traditional hanging art as transition space will form a communicative bridge between front and back and internal and external space as well as a turning point. It plays a rather unique role in function and creative process. The transition form of traditional hangings is rich and colorful with extremely intense purpose and regularity. The application of traditional hangings will also appear frequently, because traditional hangings are equipped with relatively high social value and humanistic value, which is elaborated as follows:

Firstly, traditional hanging decorative art has extremely high social value. Traditional hangings mainly combine traditional materials, patterns and the latest technologies together in order to carry forward the excellent Chinese traditional culture and embody new connotation. Interior designers must further understand the history, classification and usage characteristics in various regions of traditional hanging decorative art, conducting in-depth exploration into its materials, patterns, structure and artistic forms. Nowadays, technological development including modern decorative technologies change quickly, so the latest technological achievements should be applied in the modern public space design process, realizing the seamless joint of traditional culture skills and modern decorative skills. At present, some interior designers give up Chinese traditional decorative 
art, holding that the craft of such kind of Chinese style design is too complicated, time-consuming, strenuous and inefficient. It is a topic worthy of our deep thoughts.

Secondly, traditional hanging decorative art has extremely high humanistic and aesthetic value. Design provides service for people. Interior designers in designing process should firstly consider how to realize favorable connection between function and art, how to achieve the optimal effects and how to realize its humanistic and aesthetic value. The humanistic connotation of Chinese traditional hanging decorative art is mainly embodied in its materials and patterns. As for the manufacturing materials, traditional hangings mainly use wood materials, paint, pottery, bamboo or modern composite materials. It can be seen from the texture of its manufacturing materials that it contains the characteristics of Chinese elements. At the same time, lots of auspicious patterns are applied in the traditional hanging decorative patterns. For example, dragon and phoenix pattern represents status and power, which can usually be seen in Chinese royal palace design; while Ruyi pattern is also usually seen which represents modern people's pursuit of luckiness; Pi Xiu and shoe-shaped gold ingot patterns are applied in hangings which represents amass fortunes; peony pattern means riches and honour; similarly, some green plant images represent modern people's anticipation of life. Applying the above traditional patterns in traditional hanging decoration can not only generate beauty and decoration but also express modern people's pursuit of happy life. Therefore, ordinary people can love such kind of public places more. In addition, diversity of traditional decorative art also provides even richer visual perception for modern design, so public space design becomes a poster visible for everyone with its publicity greatly exceeding print ads.

\section{Conclusion}

To sum up, culture, which has irreversibility, is always the generic term of material civilization and spiritual civilization created by mankind in all kinds of social practice. Even though art workers in all ages attempt to get rid of traditional culture constraint and create new artistic miracle, traditional culture can be seen everywhere. For example, until now traditional hanging decorative art is still popular in modern interior design and has become a significant element of current interior design engineering. Modern designers should realize the close combination of Chinese traditional culture and modern design ideas, which ask them to improve their own historic and cultural quality, make more exploration of decorative art in traditional culture, and actively collect all kinds of materials especially the design elements with national characters. On this basis, traditional culture should be comprehensively integrated into modern design in accordance with contemporary interior design trend, so that traditional hanging decorative art can irradiate new vitality and energy and add luster to modern people’s life.

\section{References}

[1] Mu Qicong. Application of fiber art in modern interior design. Journals of Lanzhou Institute of Education, 2010(2).

[2] Yang Jiong, Zhang Chaoping. Application research on national ornament in interior design. Grand Stage, 2012(5).

[3] Tao Ruifeng, Zhang Yanmei. Application and inheritance of Manchu traditional living-room decorative elements in modern interior design. Literature in the Times, 2012(12).

[4] Wu Jie. Artistic characteristics analysis on arch hangings in Qiao's Grand Courtyard . Art Panorama, 2013(8).

[5] Wan Xiaohua, Zu Guodong, Liu Wang. Application research on Chinese classical garden art in modern interior space design. Modern Decoration (theory), 2013(11). 